\title{
Voiding Disorders in Patients with Cerebrovascular Accident
}

\section{Md. Siddiqur Rahman ${ }^{1}$, Md.Monowarul Islam², Mohammad Asaduzzaman ${ }^{3}$, Shahana Afroze ${ }^{4}$, Is motAra Zannat $^{5}$, Mohammad Mahbubul Haque ${ }^{6}$}

Received: 02 - 06 - 2020

Accepted: 05 - 09 - 2020

Conflicts of interest: None

Keywords: voiding disorders, cerebrovascular accident

\begin{abstract}
Background: Cerebrovascular accident often happens in elderly group, frequently causing voiding dysfunction. The aim of the study was to determine the magnitudes of various types of voiding disorders among patients of cerebrovascular accidents attending in Dhaka Medical College Hospital.
\end{abstract}

Methods: It was a cross-sectional study conducted at the department of Urology ofDhaka Medical College Hospital from July 2009 to June 2011. Hundred and eight patients were enrolled in the study.

Results: More than $61 \%$ subjects were male $(n=66)$.Leading number of patients $(45.4 \%)$ had three to six months disease duration. In this group $67.3 \%$ had overactive bladder, $64.7 \%$ had underactive bladder and $24.5 \%$ had normal activity of bladder. In patients with irritative symptoms majority had overactive bladder (71.4\%) while in patients with obstructive symptoms half of the subjects had overactive bladder (50.0\%). Majority of the subjects with DM (71.4\%) and HTN (82.6\%) had overactive bladder. Seventy percent $(n=)$ subjects with overactive bladder had arterial stroke while around $82 \%$ $(n=)$ of the underactive bladder subjects had venous stroke. More than $85 \%$ subjects with underactive bladder and around $78 \%$ subjects with overactive bladder had infection.

Conclusion: Voiding dysfunction is a common sequel of acute stroke and most of the patients with irritative symptoms and about half of the subjects with obstructive symptoms had overactive bladder. Diabetes mellitus, hypertension and arterial stroke were found to be associated with overactive bladder.

\section{Introduction}

Cerebrovascular accident (CVA) or stroke is a serious neurological event primarily affecting the elderly causing temporary or permanent morbidity. Impairment of voiding control is one the most critical sequelae of stroke which makes CVA important to urologists. More than 500,000 CVAs occur annually in the United States, and one third of them are fatal, another third required long-term medical care and the remaining third allow patients to return home with restored function. ${ }^{1}$ Hypertension, diabetes mellitus, smoking, raised serum cholesterol, alcohol

1. Assistant Professor, Genito-Urinary Surgical Oncology Department, National Institute of Cancer Research \& Hospital (NICRH), Dhaka

2. Assistant Professor, Genito-Urinary Surgical Oncology Department, National Institute of Cancer Research \& Hospital (NICRH), Dhaka

3. Assistant Professor, Medical Oncology Department (NICRH)

4. Senior Medical Officer, Islamic Mission, Islamic Foundation Bangladesh

5. Registrar, Paediatric Hematology and Oncology department (NICRH)

6. Associate Professor, Department of Medicine, Sheikh Hasina Medical College, Jamalpur

Correspondence: Dr. Md. Siddiqur Rahman, Assistant Professor, Genito-Urinary Surgical Oncology Department, National Institute of Cancer Research \& Hospital, Dhaka, Bangladesh. E-mail: dsr_bangladesh@yahoo.com 
consumption, obesity, stress and a sedentary lifestyle are the major risk factors for cerebrovascular accident. ${ }^{2-5}$ Recently the incidence of cerebrovascular accident in individuals older than 70 years and the mortality rate have been decreasing, ${ }^{6,7}$ but the disease burden remains high. A cerebrovascular accident may have a profound effect on the genitourinary tract. A particular problem is voiding dysfunction, which may range from urinary retention to complete incontinence. ${ }^{8-12}$ Significant sexual dysfunction is another possible effect. However, because cerebrovascular accidents occur predominantly in the elderly population, evaluation and management are often complicated by coexisting genitourinary dysfunction, such as bladder outlet obstruction in men or stress urinary incontinence in women. Also, various co-morbid conditions, including diabetes mellitus, vascular dysfunction and coronary artery disease, may affect the genitourinary system. Furthermore, changes secondary to aging, such as bladder instability, change in circadian rhythm, hormonal decrease and cognitive impairment may disturb the function of the genitourinary tract. The effects of any of these conditions may be erroneously attributed to a cerebrovascular accident and increase the difficulty of management. Some urological findings help when assessing the overall condition of the stroke patient. Particularly urinary incontinence immediately after a stroke implies a poor overall prognosis. ${ }^{13,14}$ Wade and Hewer followed 532 patients beginning shortly after the onset of a cerebrovascular accident and observed that those with urinary incontinence within the first week fared poorly with half dying within 6 months. 16 Incontinence at 3 weeks also predicted a higher risk of death as well as a lesser chance of regaining mobility. Moreover, of the $44 \%$ of patients with urinary incontinence $63 \%$ had an alteration in the level of consciousness, whereas only $1 \%$ of the 300 continent patients had a similar change. Taub et al. reviewed 639 registered cerebrovascular accident patients for disability at 3 and 12 months, and noted that initial incontinence was the best single indicator of future disability with $60 \%$ sensitivity and $78 \%$ specificity. 13 Given these data it is clear that urologists are frequently called on to evaluate and treat the stroke patient.

\section{Materials \& Methods}

This cross-sectional observationstudy was carried out at the department of Urology, Dhaka Medical College Hospital from July 2009 to June 2011. Hundred and eight patients aged $>40$ years having voiding dysfunction attending in the department of Urology of Dhaka Medical College Hospital and Neurology department was included in the study by using purposive sampling technique.

A comprehensive history was obtained \& physical examination was performed in all patients after CVA with voiding dysfunction \& all patients underwent multichannel urodynamic study by a $10 \mathrm{~F}$ filling catheter into the bladder \& simultaneously measurement of vesicle \& abdominal pressure during filling \& voiding. Voiding symptoms were classified as obstructive, irrigative or mixed.

Ethical permission was taken from Dhaka medical college Ethical Review Committee for data collection. Consent was received from each individual prior to inclusion. They were informed of their right to withdraw from the study at any stage. Assurance had been given that the data would be collected anonymously and the confidentiality concerning their information would be maintained strictly. The research was conducted in full accord with ethical principles.

The data were analyzed with the SPSS for Windows (IBM SPSS Statistics for Windows, version 25.0, Armonk, NY:IBM Corp.) software. The result was presented in tables, figures, and diagrams. Using t test, chi square and other statistical test was done for significance of difference. A P value $<0.05$ was considered as level of significance.

\section{Results}

Out of 108 patients 66 (61.1\%) were male (Fig. 1). Regarding duration of the disease more than one third of the subjects were in 91 to 180 days group (45.4\%) followed by 1 to 90 days duration group (38.9\%) (Fig. II). In the early mentioned group $67.3 \%$ had overactive, $24.5 \%$ had underactive and $8.2 \%$ had normoactive bladder (Table I). Among the subjects with irritative symptoms majority had overactive bladder $(71.4 \%)$ followed by underactive bladder $(22.1 \%)$ and normally active bladder $(6.5 \%)$. Among the subjects with obstructive symptoms half of the subjects had overactive bladder $(50.0 \%)$ followed by underactive bladder $(45.5 \%)$ and normally active bladder (4.5\%). On the other hand among the subjects who had both irritative and obstructive symptoms overactive bladder and normally active bladder constitutes the same proportion (44.4\%) (Table II). 
Majority of the subjects with DM (71.4\%) and HTN $(82.6 \%)$ had overactive bladder. About $72 \%$ subjects with both DM and HTN had overactive bladder. 78.3\% study subjects with no chronic diseases had underactive bladder. Statistically these differences were highly significant (Table III).

On the other hand majority subjects with overactive bladder had arterial stroke(70.0\%). Most of the underactive bladder subjects had venous stroke $(82.1 \%)$ (Table -IV). The proportion of arterial and venous stroke among the subjects with normal active bladder were equal(50.0\%). These differences were statistically highly significant.

More than two thirds of the subjects with overactive subjects had infection (78.6\%) and importantly infection rate was $85.7 \%$ in underactive bladder. Infection was present in $70.0 \%$ cases among subjects with normal active bladder. Statistically these differences were significant (Table V).

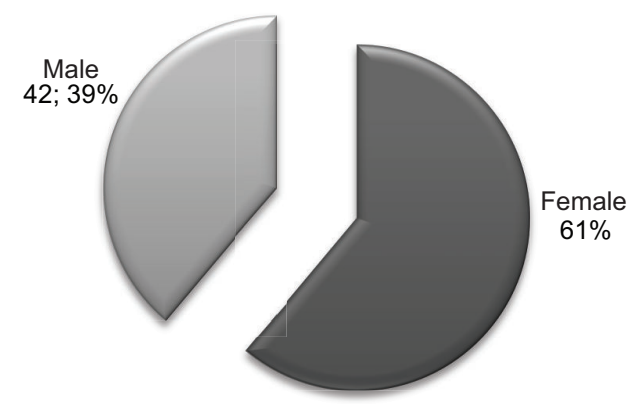

Fig.-1: Sex distribution of the study subjects

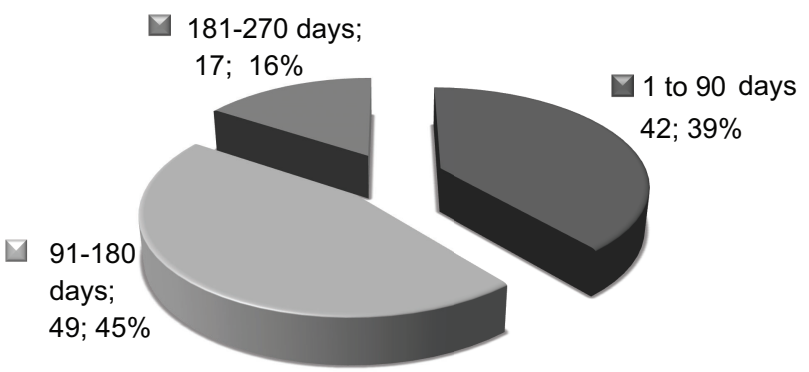

Fig.-2: Distribution of the study subjects by duration of symptoms

Table-I : Relation of duration of symptoms with bladder activity among the study subjects

\begin{tabular}{lccccc}
\hline $\begin{array}{l}\text { Duration of } \\
\text { symptoms (days) }\end{array}$ & $\begin{array}{c}\text { Overactive } \\
\text { bladder }\end{array}$ & $\begin{array}{c}\text { Underactive } \\
\text { bladder }\end{array}$ & $\begin{array}{c}\text { Normal activity } \\
\text { of bladder }\end{array}$ & $\chi^{2}$ test & $p$-value \\
\hline $1-90(\mathrm{n}, \%)$ & $26(61.9)$ & $12(28.6)$ & $4(9.5)$ & 0.475 & $0.976(\mathrm{~ns})$ \\
$91-180(\mathrm{n}, \%)$ & $33(67.3)$ & $12(24.5)$ & $4(8.2)$ & & \\
$181-270(\mathrm{n}, \%)$ & $11(64.7)$ & $4(23.5)$ & $2(11.8)$ & & \\
\hline
\end{tabular}

ns=Not significant

Table-II : Relation of types of symptoms with bladder activity among the study subjects

\begin{tabular}{lccccc}
\hline $\begin{array}{l}\text { Types of } \\
\text { symptoms }\end{array}$ & $\begin{array}{c}\text { Overactive } \\
\text { bladder }\end{array}$ & $\begin{array}{c}\text { Underactive } \\
\text { bladder }\end{array}$ & $\begin{array}{c}\text { Normal activity } \\
\text { of bladder }\end{array}$ & $\chi^{2}$ test & $p$-value \\
\hline Irritative $(\mathrm{n}, \%)$ & $55(71.4)$ & $17(22.1)$ & $5(6.5)$ & 19.47 & $0.001(\mathrm{~s})$ \\
Obstructive $(\mathrm{n}, \%)$ & $11(50.0)$ & $10(45.5)$ & $1(4.5)$ & & \\
Mixed $(\mathrm{n}, \%)$ & $4(44.4)$ & $1(11.1)$ & $4(44.4)$ & & \\
\hline
\end{tabular}

$\mathrm{s}=$ Significant

Table-III. Chronic diseases related Bladder activity among the study subjects

\begin{tabular}{lccccc}
\hline Chronic disease & $\begin{array}{c}\text { Overactive } \\
\text { bladder }\end{array}$ & $\begin{array}{c}\text { Underactive } \\
\text { bladder }\end{array}$ & $\begin{array}{c}\text { Normal activity } \\
\text { of bladder }\end{array}$ & $\chi^{2}$ test & $p$ - value \\
\hline DM $(\mathrm{n}, \%)$ & $15(71.4)$ & $2(9.5)$ & $4(19.0)$ & 45.417 & $0.001(\mathrm{~s})$ \\
HTN $(\mathrm{n}, \%)$ & $38(82.6)$ & $4(8.7)$ & $4(8.7)$ & No chronic disease \\
Both DM and HTN $(\mathrm{n}, \%)$ & $13(72.2)$ & $49(22.2)$ & $1(5.6)$ & \\
$(\mathrm{n}, \%)$ & $4(17.4)$ & $18(78.3)$ & $1(4.3)$ & \\
\hline
\end{tabular}

DM=Diabetes mellitus; HTN=Hypertension; s=Significant 
Md. Siddiqur Rahman et al

Table- IV : Association of bladder activity d with type of stroke among the study subjects

\begin{tabular}{lcccc}
\hline Bladder activity & Arterial stroke (Ischaemic) & Venous stroke & $\chi^{2}$ test & $p$-value \\
\hline Overactive $(\mathrm{n}, \%)$ & $49(70.0)$ & $21(30.0)$ & 22.034 & $0.001(\mathrm{~s})$ \\
Underactive $\mathrm{r}(\mathrm{n}, \%)$ & $5(17.9)$ & $23(82.1)$ & & \\
Normal activity $(\mathrm{n}, \%)$ & $5(50.0)$ & $5(50.0)$ & & \\
\hline
\end{tabular}

$\mathrm{s}=$ Significant

Table- V: Association of bladder activity with presence of infection among the study subjects

\begin{tabular}{lcccc}
\hline Bladder activity & Infection present & Infection absent & $\dot{\div}^{2}$ test & $p$-value \\
\hline Overactive $(\mathrm{n}, \%)$ & $15(21.4)$ & $55(78.6)$ & 13.27 & $0.001(\mathrm{~s})$ \\
Underactive $\mathrm{r}(\mathrm{n}, \%)$ & $4(11.3)$ & $24(85.7)$ & & \\
Normal activity $(\mathrm{n}, \%)$ & $3(30.0)$ & $7(70.0)$ & & \\
\hline
\end{tabular}

$\mathrm{s}=$ Significant

\section{Discussion}

In this study more than half of the subjects were male $(61.1 \%)$ and $42(38.9 \%)$ were female. This finding is comparable with that of the Anupom et al. ${ }^{15}$ study where out of 40 patients 22 (55\%) were male. However, in another study Natsume reported higher preponderance of male (34 out of $57,70 \%$ ) than others. ${ }^{16}$ In the current study more than one third of the subjects were in ninety one to one eighty days group $(45.4 \%)$ followed by 1 to 90 days duration group $(38.9 \%)$. Rests were in 181 to 270 days duration group (15.7\%).

Among the 1 to 90 days duration groups more than half of the subjects had overactive bladder (OBA) $(61.9 \%) .28 .6 \%$ had underactive bladder (28.6\%). Only 9.5\% had normal activity of bladder. Similarly 91 to 180 days duration group and 181 to 270 days duration group this proportion was $67.3 \%$ and $64.7 \%, 24.5 \%$ and $23.5 \%, 8.2 \%$ and $11.8 \%$ respectively. But all these differences were not statistically significant. In a study Hashim \& Abrams. ${ }^{17}$ determined how well the symptoms of OAB syndrome correlate with urodynamic DO using International Continence Society definitions. They found that there was a better correlation in results between $\mathrm{OAB}$ symptoms and the urodynamic diagnosis of Detrusor overactivity (DO) in men than in women.

Among the subjects with irritative symptoms majority had overactive bladder $(71.4 \%)$ followed by underactive bladder $(22.1 \%)$ and normally active bladder (6.5\%). Among the subjects with obstructive symptoms half of the subjects had overactive bladder
(50.0\%) followed by underactive bladder $(45.5 \%)$ and normally active bladder (4.5\%). On the other hand among the subjects who had both irritative and obstructive symptoms overactive bladder and normally active bladder constitutes the same proportion (44.4\%). Rests had underactive bladder (11.1\%).Statistically these differences were significant. In another study Victor et al. ${ }^{18}$ (1996) stated that among the 38 men $16(42 \%)$ were irritative, $13(34 \%)$ were obstructive and $9(24 \%)$ were mixed. In a large cohort of 935 consecutive patients with acute stroke in Denmark, $36 \%, 11 \%$, and $53 \%$ of the patients had full urinary incontinence, partial urinary incontinence, and no urinary incontinence at admission, respectively; the corresponding figures at 6-month follow-up were $8 \%$, $11 \%$, and $81 \%$, respectively. ${ }^{19}$

Urodynamically 24 patients (63\%) had obstruction, 9 patients (24\%) had no obstruction and $5(13 \%)$ had equivocal findings. Detrusor hyperreflexia was noted in $23(92 \%)$ of 25 patients of mixed (irritative and obstructive) and $8(62 \%)$ of 13 patients with obstructive type. Statistically these findings were significant and support our study findings. In the current study majority of the subjects with DM (71.4\%) and HTN $(82.6 \%)$ had overactive bladder and $72.2 \%$ subjects with both DM and HTN had overactive bladder. Around 78\% study subjects with no chronic diseases had underactive bladder. Statistically these differences were highly significant. A cross sectional study by Anupom et al. pointed out that among the patients 22 (55\%) had HTN alone, 15 (37.5\%) had DM and 10 (25\%) had both DM and HTN. ${ }^{15}$ 
In our study majority subjects with overactive bladder had arterial stroke $(70.0 \%)$. Most of the underactive bladder subjects had venous stroke $(82.1 \%)$. The proportions of arterial and venous stroke among the subjects with normal active bladder were equal $(50.0 \%)$. These differences were statistically highly significant. In Anupom et al. ${ }^{15}$ study out of 40 patients $36(90 \%)$ had arterial stroke. In Chen et al. ${ }^{17}$ study detrusor overactivity was commonly found in both ischaemic and haemorrgahic stroke patients.

It was found that more than two thirds of the subjects with overactive subjects had infection $(78.6 \%)$ and it was $85.7 \%$ with underactive bladder. Infection was present in $30.0 \%$ cases among subjects with normal active bladder. Statistically these differences were significant. Sharon et al. explained that UTI is consistently found to be one of the most frequent complications of stroke which is in line with our study findings. ${ }^{20}$

\section{Conclusion}

Voiding dysfunction is a common sequel of acute stroke and most of the patients with irritative symptoms had overactive bladder followed by underactive and normal active bladder. About half of the subjects with obstructive symptoms had overactive bladder. Diabetes mellitus, hypertension and arterial stroke were found to be associated with overactive bladder.

\section{References}

1. Kurtzke JF. Epidemiology of cerebrovascular disease. In: McDowell FH, Caplan LR, eds. Cerebrovascular Survey Report 1985. National Institute of Neurological and Communicative disorders and Stroke. Bethesda: National Institutes of Health, Public Health Service, rev. 1985, pp 1-34.

2. Love BB, Biller J, Jones MP et al. Cigarette smoking: A risk factor for cerebral infarction in young adults. Arch Neurol 1990; 47: 693.

3. SHEP Cooperative Research Group. Prevention of stroke by antihypertensive drug treatment in older persons with isolated systolic hypertension. JAMA 1993;265:3255.

4. Toni D, De Michele M, Fiorelli M et al. Influence of hyperglycaemia on infarct size and clinical outcome of acute ischemic stroke patients with intracranial arterial occlusion. J Neurol Sci 1994;123:129.

5. Roger VL, Go AS, Lloyd-Jones DM et al. Heart disease and stroke statistics-2011 update: a report from the American Heart Association Circulation. 2011;123(4):e18-e209. doi:10.1161/CIR.0b013 e3182009701.

6. May DS and Kittner SJ. Use of Medicare claims data to estimate national trends in stroke incidence, 1985-1991. Stroke 1994;25:2343.

7. Klag MJ, Whelton PK and Seidler AJ. Decline in US stroke mortality: Demographic trends and antihypertensive treatment. Stroke 1989;20:14.

8. Gross JC. Bladder dysfunction after a stroke-it's not always inevitable. J Gerontol Nursing 1990;16:20.

9. Arunabh MB and Badlani GH. Urologic problems in cerebrovascular accidents. ProblUrol 1993;7:41.

10. Badlani GH, Vohara S and Motola JA. Detrusor behavior in patients with dominant hemispheric strokes. Neurourol Urodyn 1991;10:119.

11. Gelber DA, Good DC, Laven LJ et al. Causes of urinary incontinence after acute hemispheric stroke. Stroke 1993;24: 378.

12. Khan Z, Hertanu J, Yang WC et al. Predictive correlation of urodynamic dysfunction and brain injury after cerebrovascular accident. J Urol 1981;126:86.

13. Taub NA, Wolfe CD, Richardson E et al. Predicting the disability of first-time stroke sufferers at 1 year. 12-Month follow-up of a population-based cohort in Southeast England. Stroke 1994;25:352.

14. Wade DT and Hewer RL. Outlook after an acute stroke: urinary incontinence and loss of consciousness compared in 532 patients. Quart J Med 1978;56:601.

15. Anupam G, Arun B, Taly AS, Murali T. Urodynamics post stroke in patients with urinary incontinence: Is there correlation between bladder type and site of lesion?, Ann Indian AcadNeurol 2009; 12:104-107.

16. Natsume O, Yasukawa M, Yoshii M, Takahashi S, Yamamoto M., Momose H, Suemori T, Yamada 
Md. Siddiqur Rahman et al

K, Shiomi T. Transurethral resection of theprostate in the urological management for patients with stroke, Acta Urol. Jap. 1992; 38:1123.

17. Hashim $\mathrm{H}$, Abrams $\mathrm{P}$. Is the bladder a reliable witness for predicting detrusor overactivity? J Urol 2006;175:191-194.

18. Victor WN, Howard A, Andrew JC, Role of urodynamic in the evaluation of voiding dysfunction in man after cerebrovascular accident 1996; 155: 263-266.

19. Nakayama H, Jorgensen HS, Pedersen PM, Raaschou HO, Olsen TS. Prevalence and risk factors of incontinence after stroke. The Copenhagen stroke study. Stroke 1997;28:58-62.

20. Sharon N, Claiborn S, Andrew J. Urinary tract infections complicating stroke mechanisms, consequence and possible solutions. J Stroke 2010; 41:180-84. 